\title{
Revista Brasileira de Enfermagem REBEn \\ Assistência de enfermagem a idosos que realizam cateterismo cardíaco: uma proposta a partir do Modelo de Adaptação de Calista Roy
}

Nursing care to elderly patients undergoing heart catheterization: a proposal according to the Adaptation Model of Calista Roy

Asistencia de enfermería a ancianos que realizan cateterismo cardíaco: una propuesta a partir del Modelo de Adaptación de Calista Roy

\section{Maria Célia de Freitas}

Enfermeria. Doutora em Enfermagem pela Universidade Estadual do Ceará. Enfermeira do Instituto Dr. José Frota, Foraleza, CE. maria.celia30@terra.com.br

\section{Mirna Fontenele de Oliveira}

Especialista. Enfermeira do Hospital de Pronto-Atendimento em CardiologiaPRONTOCARDIO, Fortaleza, CE.

\section{RESUMO}

O estudo objetivou identificar os diagnósticos de enfermagem de idosos que realizam cateterismo cardíaco, abordando os aspectos psicossociais, segundo a Teoria de Adaptação de Roy. Desenvolveu-se em hospital de pronto-atendimento em cardiologia de Fortaleza-CE, de janeiro a julho de 2005. Utilizou-se entrevista semi-estruturada, com 18 idosos de ambos os sexos, no pré-cateterismo. Na análise reconheceram-se os diagnósticos: alteração na manutenção da saúde, ansiedade, medo e alteração no processo familiar. Como intervenções propõe-se: criar um clima de confiança, antes do exame; escutar e respeitar sentimentos, crenças e valores, orientar quanto ao procedimento. A utilização desta teoria permitiu reconhecer que as pessoas, mediante estímulos, podem desencadear respostas positivas ou negativas, cabendo ao enfermeiro atuar como mediador.

Descritores: Cateterismo cardíaco, Teoria de enfermagem, Valores sociais; Adaptação psicológica.

\section{ABSTRACT}

The study aimed at identifying the nursing diagnoses related to the psychological and social aspects of elderly patients undergoing cardiac catheterization, according to the Adaptation Theory of Calista Roy. It was developed in a cardiology unit in a hospital in Fortaleza, CE, from January to July, 2005. A semistructured interview was used, with 18 elderly patients, in pre-catheterization period. The analysis identified the nursing diagnoses: alteration in the maintenance of the health, anxiety, fear and alteration in the family process. The nursing actions were: to create a trust climate for the aged before the exam; to listen and to respect feelings faiths and referring values to the situation; to guide the patient with relationships to the procedure. The use of this theory, allowed in recognizing that patients, by means of incentives, can unchain answers some positive times other negative times, fitting to the nurse to act as mediator.

Descriptors: Heart Catheterization, Nursing theory; Social values, Adaptation, psychological.

\section{RESUMEN}

El estúdio objetivó identificar los diagnósticos de enfermería abordando los aspectos psico-sociales de los pacientes que realizan cateterismo cardiaco, según la Teoría de Adaptación de Roy. Se desarrolló en la sección de cardiología de un hospital de Fortaleza-CE, de Janeiro a Julio de 2005. Se utilizó la entrevista semi-estructurada, con 18 ancianos, en el pre-cateterismo. En el análisis reconocieron los diagnósticos: alteración en la manutención de la salud, ansiedad, miedo y alteración en el proceso familiar. Entre las acciones se elaboraron las siguientes: crearse un clima de confianza para el paciente después del examen; escuchar y respetar sentimientos, creencias y valores referentes a la situación; orientar el paciente cuanto al procedimiento. La utilización de esta teoría permitió reconocer que las personas, mediante estímulos, pueden desencadenar respuestas ora positivas ora negativas, cabiendo al enfermero actuar como mediador. Descriptores: Cateterismo cardíaco; Teoría de enfermería; Valores sociales; Adaptación psicologica.

Freitas MC, Oliveira MF. Assistência de enfermagem a idosos que realizam cateterismo cardíaco: uma proposta a partir do Modelo de Adaptação de Calista Roy. Rev Bras Enferm 2006 set-out; 59(5): 642-6.

\section{INTRODUÇÃO}

Atualmente, mesmo com o avanço da ciência e da tecnologia, as doenças cardiovasculares (DCVs) continuam sendo motivo de preocupação, principalmente, pelo aumento de incidências de cardiopatias.

A respeito do assunto, verifica-se que as doenças cardiovasculares representaram, para o País, em 1994, $39,4 \%$ dos óbitos por causa conhecida em pessoas a partir dos vinte anos, sendo: $34,4 \%$ no Norte, $39,5 \%$, Nordeste, $38,9 \%$ no Sudeste, $40,9 \%$ e 37,5\% no Centro Oeste. A expressividade desses valores, tem elevado os investimentos das técnicas e das tecnologias utilizadas para a elucidação diagnóstica e terapêuticas eficazes, para o controle destas doenças ${ }^{(1)}$.
Submissão: $28 / 11 / 2005$

Aprovação: $03 / 05 / 2006$ 
Esses avanços contribuíram para o aprimoramento de estudos realizados em laboratórios de hemodinâmica, como: cateterismo cardíaco, angioplastia coronária com balão, com stent, aterectomias, valvoplastias com balão e atrioseptostomia, dentre outros, abrindo caminhos fundamentais para estudos de anatomia, fisiologia, etiologia e quadro clínico das doenças coronarianas, consideradas, até então, uma epidemia, pelo número crescente.

Estes estudos hemodinâmicos são conjuntos de técnicas invasivas, que utilizam cateteres radiopacos e substâncias radiativas (contraste), com fins diagnósticos e terapêuticos. Na atualidade, são exames de rotina, uma vez que têm potencializado a sobrevivência e favorecido uma melhor qualidade de vida a portadores de cardiopatias.

Dentre essas técnicas, encontra-se o cateterismo cardíaco, compreendido como um procedimento diagnóstico in vivo dos vasos sangüíneos e câmaras cardíacas, depois da infusão de contraste, que proporciona dados anatômicos e funcionais, orientadores da conduta terapêutica.

Este procedimento é realizado num ambiente cirúrgico hospitalar (laboratório de hemodinâmica), com anestesia local, seja do membro superior ou inferior, dependendo da situação de cada paciente, embora o local privilegiado seja o braço direito.

O desenvolvimento destas técnicas e suas aplicações ao estudo da fisiologia cardíaca humana normal, ou patológica, contribuíram de modo decisivo, para a sobrevivência de muitos doentes coronarianos ${ }^{(2)}$.

Na prática quotidiana hospitalar, observa-se uma demanda cada vez mais significativa aos laboratórios de hemodinâmica, tanto dos pacientes hospitalizados, como dos ambulatoriais, para a realização desses exames, tendo maior evidência o cateterismo cardíaco.

Como enfermeira assistencial, no convivio com estes pacientes, é possivel observar as mais diversas manifestações emocionais desencadeados pelo impacto da doença coronária, quanto à incerteza do que vai acontecer, por desconhecerem o procedimento, e a busca da compreensão do mesmo, gerando apreensões para a realização.

Nesses casos, a realização de um exame invasivo, no qual o coração e seus principais vasos são atingidos, geralmente, exacerbam sentimentos, como: medo, ansiedade, temor, preocupação, insegurança, dentre outros, pelo simbolismo de ser o órgão motor da vida. Representa para os pacientes, uma experiência preocupante e pouco agradável, em alguns momentos, pois a sua realização os faz sentir como se suas vidas tivessem ameaçadas. Freqüentemente relatam: "mexer com o coração da gente, não é brincadeira não, é coisa séria, porque se ele parar, acaba tudo, e ai está o problema".

Atender a essas necessidades expressas pelo paciente, provocou um redirecionamento nas atividades assistenciais de enfermagem, possibilitando a seus profissionais atuarem como mediadores entre a objetividade da técnicatecnológica e a subjetividade humana, tornando-o exercício de prática, uma verdadeira arte de cuidar.

Desta maneira, acredita-se na importância da abordagem e do reconhecimento dos aspectos psicossociais que permeiam o paciente, desencadeados por experiências pessoais, de familiares ou de amigos influenciando, diretamente nos seus comportamentos, atitudes e sentimentos frente ao procedimento, dificultando ainda mais, em algumas ocasiões, a realização do exame.

A equipe de saúde que trabalhanestas unidades deve dominaro conhecimento técnico-científico; intervir em situações e prestar ao paciente os cuidados necessários, habituando-se às intercorrências e complicações que possam surgir dos procedimentos. Para tanto, não deve se ater à inexperiência, à angústia e aos sentimentos do paciente, nessa situação, pois embora ela seja semelhante para a maioria, cada um se expressa de maneira diferente ${ }^{(3)}$.

Assim formulam-se as seguintes questões: o que pensa e sente o paciente quando vai se submeter ao cateterismo cardíaco? Que estratégias utilizam para enfrentare adaptar-se ao momento do pré-cateterismo?

Mediante tais questionamentos, pensa-se quea identificação dos diagnósticos de enfermagem que enfocam os aspectos psicossociais e sua análise, fundamentos na teoria de Callista Roy, possibilitará o reconhecimento e a elaboração das ações pertinentes ao desenvolvimento do cuidar, visando à obtenção de respostas positivas dos pacientes.

A constante interação das pessoas com seus ambientes está caracterizada por mudanças internas e externas nesse mundo em transformação e, para manterem sua própria integridade, adaptam-se continuamente a ele ${ }^{(4)}$.

A pessoa receptora dos cuidados de enfermagem é vista como um ser biopsicossocial, com mecanismos adaptativos inatos e adquiridos, os quais Ihe permitem adaptar-se às mudanças que ocorrem, sejam internas ou externas.

O grau de adaptação é influenciado pelo desenvolvimento de sistemas de enfrentamento regulador (transmissores químicos, neurais e endócrinos) e cogniscentes (cerebrais superiores de percepção, julgamento e emoção). Esses modos de adaptação são classificados como: modo fisiológico: determinado pelas respostas físicas e manifestações fisiológicas do organismo; modo de autoconceito: identifica os padrões de valores, crenças e emoções, ou seja, reconhece os aspectos psicológicos, morais e espirituais das pessoas; modo de junção de papéis: identifica os padrões de interação social da pessoa, ele é de natureza social e compreende papéis que a pessoa desempenha na sociedade, e modo de interdependência: identifica os valores humanos, pois sendo da natureza humana, faz referência às interações entre dar e receber amor, respeito e afeição $0^{(5)}$.

O comportamento relacionado aos seus modos é a manifestação do nivel adaptativo da pessoa e reflete o uso dos mecanismos de enfrentamento. Por isso, por meio da observação dos comportamentos da pessoa, em relação aos modos adaptativos, a enfermeira pode identificar respostas adaptativas ou ineficientes em situações de saúde e doença.

Neste caso, considera-se a doença como uma dimensão da vida da pessoa, que forma com a saúde um "contínuum" destacando-se conforme seu comportamento frente aos estímulos necessários para sua adaptação, são eles: estímulo focal: mudanças ou situações que afetam imediatamente a pessoa, tais como: o processo da doença, a imposição do procedimento ou eventos externos; estímulo contextual: todos os estímulos presentes, influenciando a resposta ao estímulo focal, por exemplo: sentimentos, o ambiente do procedimento, dentre outros; estímulo residual: são características presentes nas pessoas, relevantes à situação. Exemplo: realização de procedimentos anteriores, troca de informações com parentes ou amigos que viveram tal situação(4).

As respostas a esses estímulos são chamadas de adaptativas positivas, quando favorecem a integridade das pessoas quanto à sobrevivência, crescimento e reprodução, ou negativas, quando não contribuem para isso.

De acordo com a teorista, a função do enfermeiro, nessas situações é promover a adaptação positiva do paciente, devendo, para isso, desenvolver duas ações: avaliação e intervenção. Na avaliação, o enfermeiro identificará as situações problemas e seus respectivos estímulos; na intervenção, ele manipulará estes estímulos, de modo a eliminá-los, fazendo com que a pessoa se adapte a eles.

Sendo assim, o presente estudo tem como objetivo:

- Identificar os diagnósticos de enfermagem, abordando os aspectos psicossociais, dos pacientes que se submetem o cateterismo cardíaco, segundo a teoria de adaptação de Callista Roy.

- Elaborar intervenções de enfermagem para os diagnósticos frentea situações de não adaptações.

\section{METODOLOGIA}

Realizou-se o presente estudo, na seção de cardiologia de um hospital de pronto-atendimento em cardiologia da cidade de Fortaleza-CE, junto a pessoas idosas que freqüentam o laboratório de hemodinâmica para elucidação diagnóstica através do cateterismo cardíaco.

É um estudo do tipo transversal em que um grupo de idosos foram examinados e entrevistados em um determinado momento no tempo. Desejavase conhecer o que sabiam os idosos sobre o exame que iriam realizar. Então, a opção pelo momento pré-cateterismo, reconheceu-se como ideal, em que o 
imaginário dessas pessoas está somente direcionado ao exame.

Na realização deste estudo, levaram-se em conta as Diretrizes e Normas Regulamentares de Pesquisas do Conselho Nacional de Pesquisa, envolvendo seres humanos, Resolução 196/96 Brasi(|(6). Os participantes foram informados sobre os objetivos do estudo, a importância de contribuírem com o mesmo, sendo-lhes assegurado o anonimato e solicitado que assinassem o termo de consentimento livre e esclarecido.

A coleta dos dados aconteceu no período de janeiro a julho de 2005. A escolha de 18 depoentes, idosos, ocorreu de maneira aleatória, ficando a amostra constituída por ambos os sexos, com predomínio do sexo feminino (10 pacientes). A faixa etária variou de 60 a 80 anos, prevalecendo à idade de 60 anos, com a maioria dos participantes realizando pela primeira vez o cateterismo cardíaco (13 pacientes).

Quanto à ocupação, todas as mulheres (10) dedicavam-se a atividades do lar, enquanto a metade dos homens (4) trabalhava como autônomos, em diferentes atividades, os demais já eram aposentados. Dentre os diagnósticos clínicos que levaram à solicitação do exame, destacam-se: o infarto do miocárdio, angina instável, insuficiência coronariana e em pequena proporção, as valvopatias.

Para obtenção dos dados utilizou-se a entrevista semi-estruturada, com as seguintes questões norteadoras: porque o (a) senhor (a) vai fazer este exame? $O$ (a) senhor (a) sabe alguma coisa sobre cateterismo? Como o (a) senhor (a) se sente com o que está acontecendo? O que o preocupa no momento? 0 tempo gasto para cada entrevista foi, em média, 40 minutos.

Para realização da análise dos dados, seguiu-se um roteiro com os seguintes passos: identificação dos estímulos e dos respectivos comportamentos; reconhecimento dos diagnósticos de enfermagem (DE), segundo Roy, e elaboração de ações de enfermagem. Para responder aos objetivos do estudo, trabalharam-se, principalmente, os modos adaptativos que identificam aspectos psicossociais tais como o de autoconceito e função de papéis.

\section{RESULTADOS E DISCUSSÃO}

Para uma melhor compreensão, do que foi para o paciente fazer cateterismo cardíaco e a identificação, dos principais diagnósticos psicossociais, apresentados pelos pacientes, encontram-se, após os quatros ilustrativos, falas significativas de cada um deles.

\section{Percebendo a Doença}

"Eu senti muito mal, senti que ia morrer, atacou aquela dor o peito e nas costas, falta de ar, ai chamei a enfermeira e falei, eu vou morrer do jeito que estou, vou morrer". (I-2)

"Fiquei preocupada, com uma pontinha de esperança de que não fosse meu coração, que o problema não tivesse nele, e quando foi confirmado e falou que tinha que fazer esse cateterismo ai o mundo desabou, (choro). Eu estou muito nervosa e com muito medo, né, porque a gente nunca sabe como é que esta o organismo, se ele está bem ou não, para agüentar que mexam com o coração". (I - 3)

O fornecimento de informações e explicações, frente ao problema e conduta médica, é muito importante na fase pré-procedimento, porque além de confortar o paciente, proporciona-he segurança, diminuindo a confusão, ajuda-o a enfrentar a situação e lhe possibilita melhor desempenho do seu papel de doente ${ }^{(7)}$.

Dessa maneira, acredita-se que as ações de enfermagem, elaboradas para atender a este diagnóstico, possibilitarão o desenvolvimento de atitudes positivas, no paciente, contribuindo para que ele aceite realizá-lo sem medo ou preocupações, após as informações recebidas dos profissionais.

\section{Assimilando o Cateterismo}

"O coração envolve qualquer ser humano, só tem um, é como eu sempre falo, você tem 10 dedos, se cortar um, você joga e fica com nove, você tem duas vistas, se perde uma, com a outra enxerga, mais o coração não tem jeito, só tem ele, se ele parar acabou tudo, a vida acabou, e você morre e eu não quero isso, então choca muito, todo mundo acha que se sente chocado, só tem ele, não tem outro, você não tem outra saída, entendeu." (l-1)

"O médico me enviou pra vir pra cá a fazer esse exame, eu não queria vir não, mais disse que tenho que fazer. Ele para mim não explicou nada, só que preciso fazer isso aí, né, cateterismo, tem que provar, tem que fazer mesmo."(l-6) “...a gente fica um pouco preocupada, nervosa, nunca veio num lugar
desse, e a primeira vez, então a gente fica com medo de estarnum lugar
desconhecido, você não conhece ninguém, não sabe o que pode acontecer
e tem que confiar naquilo que vocês vão fazer com a gente, então é meio
difícil."(l-9)

"Eu tenho escutado de pessoas que fizeram que é doido, que dá enjoou, essas coisas. Falam que cortam e colocam um fiozinho que vai lá no coração, então é por isso que estou preocupada; já falaram pra mim que tem pessoas que não agüentaram fazer, as pessoas falam muito, né, você fica mais nervosa escutando essas coisas, né?" (I-10)

Ansiedade é o estado em que o indivíduo demonstra sentimentos de intranqülidade (apreensão) com ativação do sistema nervoso autônomo, em resposta a uma ameaça vaga e inespecífica ${ }^{(8)}$.

Por ser esse procedimento invasivo ao coração, mesmo que seja diagnosticado, é um momento em que todos os temores do paciente se exacerbam diante da iminência de um fato que poderáalterar o seu esquema de vida.

Neste sentido, considerou-se muito importante, dentre as ações de enfermagem, criar um espaço para o diálogo, priorizando a escuta, com o fim de explorar as causas da ansiedade e demonstrar ao paciente que suas preocuapções serão levadas em conta.

Escutar é um ato psicológico, que impõe uma disposição interna de acolher signos, ora claros, ora obscuros, em busca de algum registro que viabilize algum campo de troca (...) É uma decifração que busca captar signos através do ouvido, mediante códigos que são incorporados na vida do ser humano, através da história, culturas e experiências vividas ${ }^{(9)}$.

\section{Realizando o Cateterismo}

"Estou com medo pelas falas do povo, é boberia, mas pra que contar, para você falar não vai dar tudo certo, fica tranqüila, como vocês sempre falam pra gente, então prefiro não falar e pensar que é bobeira do povo. Às vezes, vocês não entendem o medo da gente, mas é a gente que está sentindo, que está sofrendo, então é por isso que estou chateada."(l-18)

"Estou muito nervosa, estou com medo de que aconteça alguma coisa, eu não estava com vontade de fazer de novo, sabe, isso não me deixa tranqüila. Eu não durmo desde ontem pensando no exame, estou com muito medo de morrerna hora, porque a gente nunca sabe, é o coração da gente que está nas mãos dos médicos, só eles sabem o que estão fazendo, a gente não."

"Nossa vida depende do coração, é por isso que a gente fica com medo, e se ele parar de funcionar? Eu estou muito abatida, estou com muito medo de morrer. Não sei que vaiacontecer direito, se eu vou melhorar ou vou continuar do mesmo jeito que estou, não sei se meu coração vai agüentar."

O medo como o estado em que o indivíduo apresenta um sentimento de perturbação fisiológica ou emocional relacionado a uma fonte identificável 
Assistência de enfermagem a idosos que realizam cateterismo cardíaco: uma proposta a partir do Modelo de Adaptação de Calista Roy

\begin{tabular}{|c|c|c|c|}
\hline $\begin{array}{c}\text { MODO } \\
\text { DE ADAPTAÇÃO }\end{array}$ & ESTÍMULO & $\begin{array}{l}\text { DIAGNÓSTICO DE } \\
\text { ENFERMAGEM }\end{array}$ & $\begin{array}{c}\text { AÇÕES DE } \\
\text { ENFERMAGEM }\end{array}$ \\
\hline $\begin{array}{c}\text { MODO } \\
\text { DE AUTOCONCEITO }\end{array}$ & $\begin{array}{l}\text { FOCAL: } \\
\text { *Doença: infarto do miocárdio, angina } \\
\text { e insuficiência coronária. } \\
\text { CONTEXTUAL: } \\
{ }^{*} \text { Realização do cateterismo cardíaco }\end{array}$ & $\begin{array}{l}\text { ALTERAÇÃO NA } \\
\text { MANUTENÇÃO DA SAÚDE }\end{array}$ & $\begin{array}{l}\text { - Explicar com palavras da linguagem do paciente, qual é a doença que tem, } \\
\text { e possíveis causas. } \\
\text {-Orientar o paciente a respeito do exame que precisa fazer para definição do } \\
\text { melhor tratamento para ele. } \\
\text {-Permitir ao paciente expressar suas dúvidas, inquietações e preocupações. }\end{array}$ \\
\hline $\begin{array}{c}\text { MODO } \\
\text { DE AUTOCONCEITO }\end{array}$ & $\begin{array}{l}\text { FOCAL: } \\
\text { *Significado do órgão doente } \\
\text { *Imposição do cateterismo cardíaco } \\
\text { CONTEXTUAL: } \\
\text { *Desconhecimento do exame } \\
\text { *Ambiente hospitalar } \\
\text { *Expectativa do exame } \\
\text { *Falta de comunicação entre a equipe } \\
\text { e o paciente. } \\
\text { RESIDUAL: } \\
\text { *Informações sobre experiências de } \\
\text { conhecidos } \\
\text { *Informações transmitidas entre } \\
\text { amigos e familiares }\end{array}$ & ANSIEDADE & $\begin{array}{l}\text {-Dar ao paciente a possibilidade de expressar seu consentimento para } \\
\text { realizar o exame, caso contrario, explicar-lhe a importância do mesmo e os } \\
\text { benefícios para melhorar sua condição. } \\
\text {-Procurar manter uma atitude receptiva e de interesse para com o paciente; } \\
\text { olhar sempre para ele; escutá-lo atentamente. } \\
\text {-Fazê-lo sentir-se a pessoa mais importante no momento, para poder criar } \\
\text { um clima de confiança antes do exame. } \\
\text {-Permitir ao paciente manifestar seus sentimentos, a fim de compreender sua } \\
\text { vivência e aplicar estratégias de apoio e confiança. } \\
\text {-Orientá-lo sobre o exame que vai fazer o que vai encontrar na sala, o que } \\
\text { pode sentir, como vai ser, de modo compreensível para ele, e perguntando } \\
\text { sempre suas dúvidas. } \\
\text {-Se possível, comunicar-Ihe sobre a equipe que vai estar junto com dele. } \\
\text { Explicar-lhe que haverá uma enfermeira ao seu lado para atendê-lo, se } \\
\text { precisar, e para quem poderá dizer o que está sentindo. } \\
\text {-Explicar-lhe que cada pessoa sente coisas de diferentes maneiras, por isso, } \\
\text { alguém pode ter-lhe dito que não sentiu nada e outras, que o exame é ruim. } \\
\text {-Evitar os falsos apoios, tais como: fique tranqüila, é uma coisa simples, não } \\
\text { é para preocupar-se. Às vezes, a pessoa fica mais irritada. } \\
\text {-Tentar transmitir sentimentos e emoções positivas de carinho, como: pegar } \\
\text { sua mão, acariciar sua pele etc. } \\
\text {-Tentar fazer do momento de espera uma situação menos tensa. Criar um } \\
\text { ambiente para falar com todos os pacientes, sobre os temas que eles } \\
\text { queiram sorrir para eles, enfim, distrai-los. }\end{array}$ \\
\hline $\begin{array}{c}\text { MODO } \\
\text { DE AUTOCONCEITO }\end{array}$ & $\begin{array}{l}\text { FOCAL: } \\
\text { Realização do cateterismo } \\
\text { CONTEXTUAL: } \\
\text { "Medo da morte } \\
{ }^{*} \text { Medo do desconhecido } \\
{ }^{*} \text { Incerteza quanto ao que pode } \\
\text { acontecer no procedimento } \\
\text { *Incerteza quanto à habilidade técnica } \\
\text { do profissional } \\
\text { *Preocupação com o resultado } \\
\text { RESIDUAL: } \\
\text { "Experiências anteriores } \\
\text { "Relatos de depoimentos de amigos e } \\
\text { familiares }\end{array}$ & MEDO & $\begin{array}{l}\text { - Escutar atentamente seus medos, preocupações, ou seja, os sentimentos } \\
\text { que estão tornado esse momento ainda mais difícil. } \\
\text { - Ressaltar as vantagens da realização do exame, que poderá determinar o } \\
\text { tratamento mais apropriado. } \\
\text { - Explicar-lhe que o exame hoje em dia é realizado com muita freqüência e } \\
\text { cada vez a equipe está mais preparada para realizá-lo e atuar diante de } \\
\text { qualquer eventualidade. } \\
\text { - Repetir que na medida do possível haverá um profissional ao seu lado, } \\
\text { dando-lhe apoio durante o exame. } \\
\text { - Informá-lo sobre os membros da equipe, os aparelhos da sala, as } \\
\text { vestimentas cirúrgicas da equipe e o que vai acontecer durante o exame, } \\
\text { para que o paciente tenha idéia da situação. } \\
\text { - No caso de ter passado pela experiência do cateterismo, perguntar como } \\
\text { ela foi e explicar-lhe tudo novamente, procurando encontrar diferenças } \\
\text { positivas para encorajá-lo. } \\
\text { - Compartilhar com ele a espera para a realização do exame, a fim de criar } \\
\text { um ambiente de confiança e segurança. }\end{array}$ \\
\hline $\begin{array}{c}\text { MODO } \\
\text { DA FUNÇÃO DE PAPEL }\end{array}$ & $\begin{array}{l}\frac{\text { FOCAL: }}{\text { *Doença }} \\
\text { *Realização do cateterismo } \\
\text { CONTEXTUAL: } \\
\text { *Interrupção laboratorial } \\
\text { *Internação hospitalar } \\
\text { *Responsabilidades familiares } \\
\text { *Incerteza quanto ao futuro } \\
\text { RESIDUAL: } \\
\text { *Sentimentos de impotência }\end{array}$ & $\begin{array}{l}\text { ALTERAÇÃO NO } \\
\text { PROCESSO FAMILIAR }\end{array}$ & $\begin{array}{l}\text { - Enfatizar que o exame será importante para o diagnóstico e tratamento do } \\
\text { problema, capacitando-o à retomada de suas atividades e responsabilidades, } \\
\text { tanto familiares quanto laborais, de acordo com algumas indicações. }\end{array}$ \\
\hline
\end{tabular}

\section{Quadro 1. Avaliação psicossocial dos participantes quanto aos Modos de Autoconceito e Função de Papel, segundo Roy(4).}

percebida como perigosa ${ }^{(8)}$.

O medo, a apreensão e a insegurança, podem diminuir quando ocorre o estabelecimento de um diálogo compreensível, tendo o paciente oportunidade para expressar suas necessidades e receber informações sobre o desconhecido, ou seja, o procedimento em que vai estar envolvido. Dessa maneira, aumentarão a cooperação, a confiança e a segurança, favorecendo o bem-estar da pessoa ${ }^{(10)}$.

Considera-se, então, que dentre as ações de enfermagem, mais importantes estão às orientações dadas ao paciente, que somadas ao calor humano, irão ajudá-lo a vencer o medo nesse momento difícil e incerto, proporcionando-lhe alívio e conforto.

\section{Assimilando a Doença}

"Eu tenho muita coisa pela frente, né, uma vida ativa, quero viver, preciso viver por minha família ainda." (I-11)
"Eu sinto que tem vez que ele da uma paradinha, ai é o medo, se ele não agüentar hoje e ficar parado pelo resto da vida, não posso ir embora, meu filho precisa muito de mim ainda."(l-13)

"Ficar aqui não é fácil, você é um estranho, você não entende direito o que os médicos falam, então você fica medroso." (I-15)

"Quando o médico falou que tive um infarto, fiquei meio ruim, viu, porque eu digo uma coisa, eu vou fazer 48 anos agora, né, então aí fiquei naquele negócio, tenho muito para viver e trabalhar ainda, entendeu, eu já fiquei com a cabeça pensando se não posso voltar a trabalhare isso que me abala." (l-12)

Esta alteração no processo familiar se dá porque tanto o homem como a 
mulher têm responsabilidades e tanto a doença como a incerteza do que ocorrerá daí para frente, criarão neles maior preocupação, aumentando a dificuldade para assumirem atos de responsabilidade e para conduzirem a família. Em alguns casos, é mais relevante sua função social que a resolutividade do problema em si.

\section{CONSIDERAÇÕES FINAIS}

Acredita-se que 0 atendimento das necessidades psicossociais proporciona ao paciente a oportunidade de expressar seus sentimentos e preocupações, pois de alguma maneira influenciam de forma negativa 0 momento. Transmitir-lhe segurança emocional, atenção e apoio, é função da equipe, que com isso estará lhe proporcionando meios para desenvolver mecanismos de enfrentamento positivo para o seu bem estar.

A utilização desta teoria da Adaptação de Callista Roy ${ }^{(4)}$, permitiu reconhecer que as pessoas, mediante estímulos, podem desencadear respostas, ora positivas ora negativas, em situações estressantes, cabendo ao enfermeiro atuar como mediador entre a objetividade técnica e a subjetividade humana, elaborando estratégias para as ações do cuidar; capacitando as pessoas a criarem mecanismos de enfrentamento que possam diminuir as respostas negativas; favorecendo sua vivência e facilitando a realização do procedimento.

Considera-se que os dados obtidos poderão fornecer elementos de reflexão para a equipe de enfermagem, quanto ao valor das relações interpessoais, tido como principal recurso para o atendimento das necessidades psicossociais dos pacientes, em situações constrangedoras.

\section{REFERÊNCIAS}

1. Lessa I. Introdução à epidemiologia das doenças cardiovasculares no Brasil. In: Lessa I, et al. $\mathrm{O}$ adulto brasileiro e as doenças da modernidade - epidemiologia das doenças crônicas não transmissíveis. São Paulo (SP): Hucitec; 1998.

2. Gressman W, Barry W. Cateterismo cardíaco. In: Braunwald W. Tratado de medicina cardiovascular. $3^{a}$ ed. São Paulo (SP): Roca; 1991. p. 254-80.

3. Vital LM. Estudo sobre orientação a um grupo de pacientes em preparo para exame hemodinâmico (dissertação). São Paulo (SP): Escola de Enfermagem São Paulo, USP; 1984.

4. Roy SC. Introduction to nursing: na adaptation model. $2^{\text {nd }}$ ed. Englesood Cliffis: Prentice Hall; 1984

5. George JB. Teorias de enfermagem: os fundamentos para a prática profissional. Porto Alegre (RS): Artes Médicas; 1993.
6. Brasil. Ministério de Saúde. Diretrizes e Normas Regulamentadoras de Pesquisa envolvendo Seres Humanos. Brasília (DF): Ministério de Saúde; 1997.

7. Maldonado MT. Comunicação entre pais e filhos: a linguajem do sentir. Petrópolis (RJ): Vozes; 1983.

8. Carpenito LJ. Diagnósticos de Enfermagem: aplicação à prática clínica. 6a ed. Porto Alegre (RS): Artes Médicas; 1997.

9. Pitta AMF. Cuidando de psicóticos. In: Goldberg J. Clínica da psicoses, um projeto na rede pública. Rio de Janeiro (RJ): Editora Instituto Franco Brasaglia; 1994. p.155-6.

10. Takahashi $\mathrm{OCH}$. Necessidades psicossociais de pacientes submetidos à cirurgia do aparelho digestivo - uma assistência sistematizada (dissertação). São Paulo (SP). Escola de Enfermagem da Universidade de São Paulo, USP; 1987. 